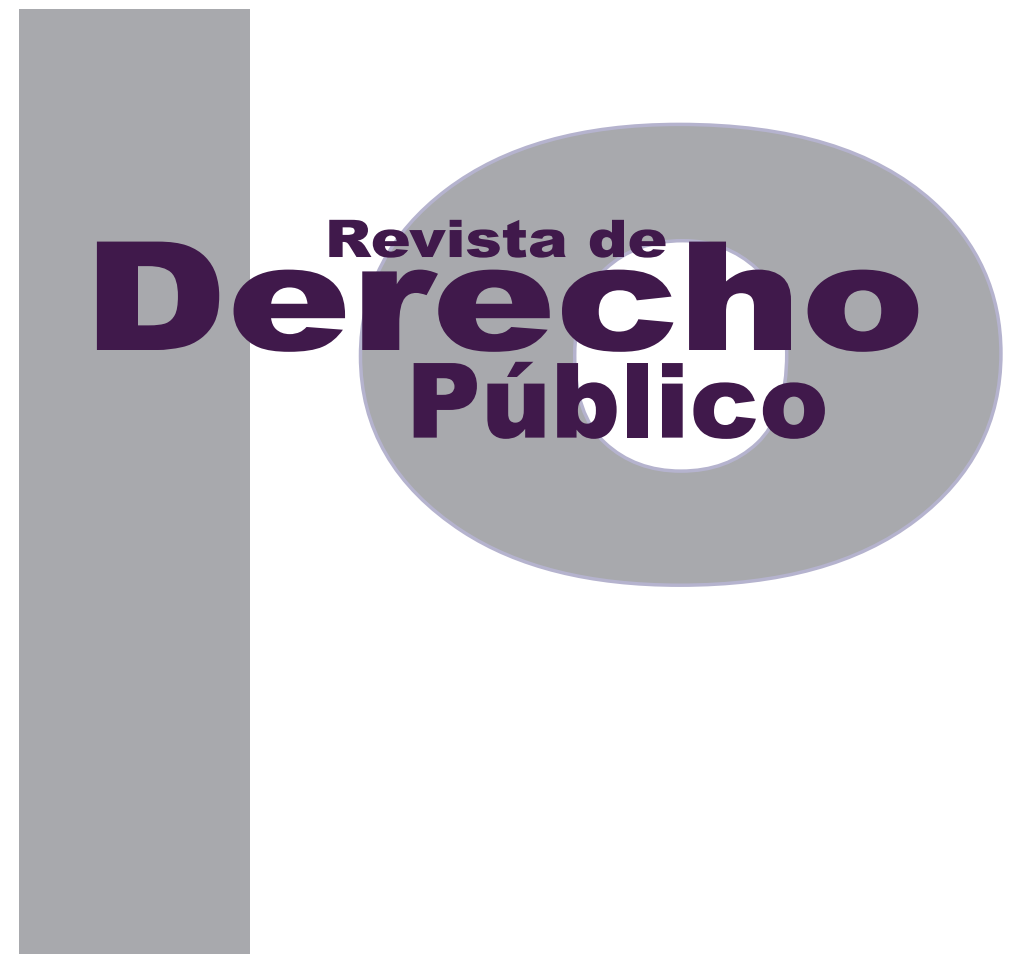

\title{
UNA PERSPECTIVA GENERAL SOBRE MUJERES Y PRISIONES EN AMÉRICA LATINA Y COLOMBIA
}

\author{
LIBARDo JosÉ ARIZA \\ MANUEl ItURRALDE \\ Artículo de reflexión \\ DOI: http://dx.doi.org/10.15425/redepub.35.2015.10 \\ Universidad de los Andes \\ Facultad de Derecho \\ Rev. derecho publico No.35 \\ julio - diciembre de 2015. ISSN 1909-7778
}




\title{
Una perspectiva general sobre mujeres y prisiones en América Latina y Colombia
}

\section{Resumen}

En este artículo analizamos la situación de la mujer privada de la libertad en el contexto latinoamericano, haciendo énfasis en el caso de Colombia. Pretendemos contribuir al debate en torno a la experiencia penitenciaria femenina, con especial atención en los siguientes aspectos: a través de la recopilación, organización y análisis de los datos disponibles sobre la población penitenciaria femenina, buscamos contribuir a llenar el vacío que existe en materia de información sobre las mujeres y el sistema penitenciario; con base en lo anterior, mostramos que el carácter diferencial de la política criminal y penitenciaria en relación con las mujeres puede hallarse en que experimentan con mayor rigor el giro punitivo tanto local como regional de las últimas décadas frente al tráfico de drogas; por último, mostramos que esta afectación especial tiende a concentrarse en mujeres que se encontraban en circunstancias previas de exclusión económica y social, fenómeno que puede describirse como una feminización punitiva de la pobreza.

Palabras clave: mujer, feminismo, criminología feminista, sistema penitenciario y carcelario, giro punitivo, narcotráfico, políticas de drogas, feminización de la pobreza.

\section{An overview on women and prisons in Latin America and Colombia}

\begin{abstract}
In this paper we analyze the situation of women who have been imprisoned in Latin America prisons, with an emphasis on Colombia. We seek to contribute to the debate on the experience of incarcerated women through the collection, organization and analysis of available data on the female prison population. Using this information we seek help fill the gap in terms of information on women and the prison system. Based on the above methodologies, we are able to show that the differential nature of criminal and prison policies in relation to women can be found in that they experience a more strictly punitive approach both locally and regionally in recent decades with regards to drug trafficking crimes. Finally, we show that this approach tends to focus on women who were economically disadvantaged and social excluded prior to their incarceration, a phenomenon that can be described as the punitive feminization of poverty.
\end{abstract}

Keywords: woman, feminism, feminist criminology, prison system, punitive approach, drug trafficking, drug policy, feminization of poverty.

\section{Uma perspectiva geral sobre mulheres e prisões na América Latina e na Colômbia}

\section{Resumo}

Neste artigo analisamos a situação da mulher privada da liberdade no contexto latino-americano, enfatizando o caso da Colômbia. Pretendemos contribuir com o debate sobre a experiência penitenciária feminina, com atenção especial nos seguintes aspectos: através da recopilação, organização e análise dos dados disponíveis sobre a população penitenciária feminina, buscamos contribuir a preencher o vazio que existe em matéria de informação sobre as mulheres e o sistema penitenciário; com base no anterior, mostramos que o caráter diferencial da política criminal e penitenciária em relação com as mulheres pode encontrar-se em que experimentam com maior rigor o giro punitivo tanto local quanto regional das últimas décadas frente ao tráfico de drogas; por último, mostramos que esta afetação especial tende a concentrar-se em mulheres que se encontravam em circunstâncias prévias de exclusão econômica e social, fenômeno que pode descrever-se como una feminização punitiva da pobreza.

Palavras-chave: mulher, feminismo, criminologia feminista, sistema penitenciário e carcerário, giro punitivo, narcotráfico, políticas de drogas, feminização da pobreza. 


\title{
Una perspectiva general sobre mujeres y prisiones en América Latina y Colombia*
}

\author{
Libardo José Ariza \\ Manuel lturralde
}

\section{SUMARIO}

Introducción - I. UNA PERSPECTIVA GENERAL SOBRE CÁRCELES Y MUJERES EN AMÉRICA LATINA - A. Malas madres - B. El narcotráfico como delito de dominio femenino - II. EL PERFIL DE LAS MUJERES PRESAS EN COLOMBIA - A. La población reclusa femenina: número de detenidas, situación jurídica e infraestructura disponible - B. Edad, nivel educativo, entorno familiar y social - C. Delitos, tiempos de condena y acceso a actividades de resocialización - III. Conclusiones - Referencias.

Cómo citar este artículo: Ariza, L. J. e Iturralde, M. (Diciembre, 2015). Una perspectiva general sobre mujeres y prisiones en América Latina y Colombia. Revista de Derecho Público, 35. Universidad de los Andes (Colombia).

Agradecemos la valiosa colaboración de la estudiante de Derecho y asistente de investigación Mabel Carmona, quien recopiló, organizó y analizó las cifras disponibles sobre la población reclusa en Colombia entre 1990 y 2013 que se incluyen en el presente capítulo; igualmente la asistencia de Mario Andrés Torres en la revisión de este texto y su ajuste al formato propio de esta publicación.

** Profesor asociado, Facultad de Derecho Universidad de los Andes. Correo electrónico: lj.ariza20@uniandes.edu.co

*** Profesor asociado, Facultad de Derecho Universidad de los Andes. Correo electrónico: miturral@uniandes.edu.co 
Introducción

A pesar de su relevancia, la situación de las mujeres privadas de la libertad en Colombia y América Latina es un asunto que no ha ocupado un lugar central en la agenda de los diseñadores de políticas públicas y de académicos, al menos por tres razones distintas pero estrechamente relacionadas entre sí. En primer lugar, porque la problemática carcelaria y penitenciaria masculina domina la agenda de la política criminal. Como el crimen es cosa de hombres, la política pública diseñada para enfrentarla también debe serlo, tanto como el saber criminológico (Smart, 1995 Britton, 2000). Así, las políticas públicas, las reformas institucionales, la refacción y ampliación de establecimientos penitenciarios son procesos que parecen ser diseñados para responder, no siempre de manera explícita, a las demandas derivadas de la cuestión masculina penitenciaria, esperando que como consecuencia ineludible se afecte o transforme la situación de las mujeres privadas de la libertad. En segundo lugar, porque se asume que este predominio cuantitativo de la población penitenciaria masculina justifica la priorización de sus necesidades, las cuales no se asumen distintas a las de la población penitenciaria femenina. Por último, porque se supone que la baja representación de las mujeres en el sistema penitenciario y carcelario es una muestra de su poca relevancia en términos del control de la desviación femenina que se torna en delincuencia. En consecuencia, se supone que otras instituciones y mecanismos (el hogar, el dispositivo de alianza matrimonial, el trabajo reproductivo) asumirán la tarea de controlar a las mujeres, alejándolas del campo criminal. Cuando, desde este último punto de vista, se indaga por la criminalidad femenina, se tiende a concluir que esta resulta de una doble desviación: de una ruptura doble de la norma natural que ordena su lugar en la sociedad, y de la norma jurídica que ordena su comportamiento como ciudadana.

Estas tres razones, en nuestra opinión, pueden explicar en parte esta suerte de invisibilidad de la mujer en los estudios sobre el campo penitenciario y carcelario local. Para intentar contribuir a la discusión tanto académica como política sobre la experiencia penitenciaria femenina en el ámbito local y regional, en este artículo analizamos la situación de las mujeres privadas de la libertad en América Latina, así como los estudios que se han realizado al respecto, los cuales, desde una perspectiva crítica, han mostrado cómo el encarcelamiento constituye un fenómeno de opresión en contra de las mujeres, que unido a otros factores de discriminación como la clase social y la raza afecta de forma especial a las madres jóvenes cabeza de familia, quienes viven en condiciones de marginalidad y con pocas posibilidades de acceso a la educación y el mercado laboral. Así, la prisión ha contribuido, cada vez más a medida que aumenta el número de mujeres encarceladas, a lo que se ha denominado la feminización de la pobreza en América Latina (CELs, Ministerio Público de la Defensa, Procuración Penitenciaria de la Nación y Siglo xxı Editores, 2011, págs. 25-26). Con tal fin, en la primera parte de este texto esbozaremos, en términos generales, las principales lecturas 
acerca del significado y alcance del encarcelamiento femenino en la región. En la segunda parte nos concentraremos en el análisis del contexto y perfil socioeconómico de las mujeres privadas de la libertad en Colombia, rasgos que, como se verá, responden a los principales argumentos esgrimidos por las teorías crítica y feminista sobre las mujeres privadas de la libertad en torno a tres tendencias principales, esto es, la particularidad de la experiencia femenina dentro de una institución netamente masculina como la prisión, el poco interés político sobre su situación y, a pesar de ello, el crecimiento de la población penitenciaria femenina impulsado por las políticas para combatir el narcotráfico y, especialmente, su doble descalificación: como delincuentes y como malas mujeres.

\section{UNA PERSPECTIVA GENERAL SOBRE CÁRCELES Y MUJERES EN AMÉRICA LATINA}

La crítica feminista a los discursos y prácticas penales, así como a la criminología positivista, que privilegiaban una mirada androcéntrica e invisibilizaban y no daban voz a las mujeres oprimidas por el archipiélago carcelario (Carlen y Worrall, 2004), tuvo un impacto significativo en América Latina. Desde finales de los ochenta, diversas autoras analizaron el fenómeno del encarcelamiento de las mujeres en la región, también desde un enfoque de género y una mirada crítica frente al control social ejercido sobre ellas y los roles pasivos y sumisos que les eran asignados. El contexto latinoamericano también propiciaba el surgimiento de este tipo de estu- dios que, no casualmente, coincidieron con el aumento significativo del uso de la prisión como forma de control social de las mujeres desviadas, particularmente por delitos de narcotráfico.

Libros como el de María de la Luz Lima, Criminalidad femenina (1991), analizaron el tema de la transgresión femenina y de los efectos e implicaciones de la privación de la libertad en las mujeres desde una perspectiva de género (Antony 2007, pág. 73). Como señala Carmen Antony, hasta antes de que surgiera este tipo de análisis innovador, la criminología positivista en América Latina también partía de estereotipos sobre la mujer, que distorsionaban la realidad y le asignaban un rol pasivo, alejado de la criminalidad. A su vez, estos estereotipos sobre la mujer daban lugar a que en la prisión se privilegiaran las necesidades de los hombres frente a las de las mujeres, como lo evidencian la arquitectura carcelaria y los servicios que se prestan al interior de los penales (Antony, 2007, pág. 74). Si estos son precarios en la región, lo son aún más en el caso de las mujeres. Las estadísticas carcelarias también ponen de manifiesto la invisibilización de las mujeres detenidas en América Latina; no solo son escasas sino que toman solo la variable sexo, desconociendo por completo la perspectiva de género $y$, en consecuencia, los roles, valoraciones y relaciones de poderes que las afectan de forma distinta (Antony, 2007, pág. 74; Bavestrello y Cortés, 1997, pág. 15).

En concordancia con sus pares del norte global, las autoras que estudian la situación de las mujeres detenidas en la región también señalan 
cómo la prisión es un espacio opresivo y discriminador para las mujeres, quienes son doblemente estigmatizadas: por realizar conductas desviadas y por alejarse de su rol de esposas y madres sumisas, dependientes y dóciles (Antony, 2007, pág. 76; Rodríguez, 2004, pág. 12; Lagarde, 1993, pág. 676).

Antony, quien ha realizado estudios extensivos sobre mujer y prisión en América Latina, particularmente en Panamá y Chile (ver Antony, 2000), destaca la similitud de los establecimientos de reclusión para mujeres en el continente: se caracterizan por tener regímenes estrictos; las altas condenas (especialmente por narcotráfico); la alta proporción de sindicadas frente a condenadas (mayor que la de los hombres); el mal estado de la infraestructura carcelaria; la falta de atención y tratamientos médicos especializados (particularmente en lo referente a ginecología y ginecobstetricia); las formas vejatorias y de discriminación a que son sometidas durante las visitas íntimas o para poder acceder a ellas; el enfoque de las terapias penitenciarias en supuestos trastornos nerviosos, que además maternalizan e infantilizan a las mujeres presentándolas como seres subordinados, incapaces de tomar decisiones y carentes de responsabilidad; el poco acceso y la escasa calidad y utilidad de los programas de estudio y trabajo, enfocados en reforzar hábitos y ocupaciones "propios" de las mujeres: coser, planchar, cocinar, limpiar, confeccionar artesanías, cursos de modistería y, en el mejor de los casos, secretariado (2007, págs. 76-80).

Las formas de opresión y discriminación a que son sometidas las mujeres que terminan en pri- sión -concluyen varios de estos estudios-, no hacen sino agravar, durante el tiempo de reclusión y después, la situación de marginalidad y pobreza en que se encuentran estas mujeres, muchas veces a cargo de hijos pequeños y nietos, y que no cuentan con el apoyo de los padres o los abuelos. La feminización de la pobreza es un término usado de forma recurrente en estos estudios para explicar este fenómeno por medio del cual se amplía la brecha entre géneros (Antony, 2000; cels et al., 2011, págs. 25-26).

\section{A. Malas madres}

Un tema recurrente en los estudios sobre mujeres encarceladas en América Latina es su sufrimiento como madres, bien sea por abandonar a su hijos al entrar a prisión o por tenerlos presos con ellas, en condiciones deplorables y sin acceso a buenos servicios de salud, alimentación y guarderías a cargo de especialistas. ${ }^{1}$ Si bien la experiencia penitenciaria femenina no puede asimilarse a la experiencia de la mujer que es madre, existe un relativo consenso en que este es uno de los asuntos más relevantes en este campo. Diversos estudios muestran cómo una

\footnotetext{
1 Buena parte de las legislaciones latinoamericanas autorizan la estadía en prisión de los hijos con sus madres hasta los 3 o 4 años de edad. Al respecto ver, en el caso colombiano, el régimen diferenciado que establece la Ley 1709 de 2014 en los siguientes términos: "Artículo 18. Modifícase el artículo 26 de la Ley 65 de 1993, el cual quedará así: Artículo 26. Establecimientos de reclusión de mujeres. Las cárceles de mujeres son los establecimientos destinados para la detención preventiva de las mujeres procesadas. Su construcción se hará conforme a lo establecido en el artículo 17 de la Ley 65 de 1993. Las penitenciarías de mujeres son los establecimientos destinados para el cumplimiento de la pena impuesta a mujeres condenadas. Estos establecimientos deberán contar con una infraestructura que garantice a las mujeres gestantes, sindicadas o condenadas, un adecuado desarrollo del embarazo. Igualmente deberán contar con un ambiente propicio para madres lactantes que propenda al correcto desarrollo psicosocial de los niños y niñas menores de tres (3) años que conviven con sus madres".
} 
gran proporción de las mujeres encarceladas son madres cabeza de familia, con varios hijos menores de edad. De hecho, el 53\% de las mujeres presas en Colombia son madres cabeza de familia, y la mayoría de sus hijos tiene entre 4 y 10 años de edad (Briceño-Donn, 2006, pág. 30). ${ }^{2}$ En Argentina, según cels et al. (2011), en el ámbito federal el $85.8 \%$ de las reclusas encuestadas declaró ser madre, con tres hijos en promedio; el 86\% tiene hijos menores de 18 años y más de una quinta parte, hijos menores de 4 años (pág. 35). Estas mujeres manifiestan que este es el mayor dolor que les causa su estadía en prisión, incluso provocándoles trastornos físicos y mentales por el estigma de ser malas madres, que abandonan a sus hijos (muchos de ellos quedan a cargo del Estado) o los hacen sufrir por sus errores (Antony, 2006, 2007; Rodríguez, 2004, pág. 12; Marchiori, 1999, pág. 389; Lagarde, 1993; cels et al., 2011, págs. 14-15).

El hecho de que las madres tengan a sus hijos en prisión supone que se ejerza una forma de control adicional sobre ellas, ya que de no portarse bien y tener una actitud sumisa, una amenaza recurrente de las autoridades carcelarias es quitarles a sus hijos (Antony, 2007, pág. 79). Adicionalmente, el tener hijos en prisión se vuelve una forma de discriminación pues las madres, por destinar parte de su tiempo a cuidar los hijos (los servicios de guardería son

2 Las cifras sobre el perfil socioeconómico de las mujeres detenidas en Colombia son escasas y muy incompletas; por lo tanto no es fácil establecer cuáles de las que están disponibles sobre un mismo tema son las más confiables. Según el estudio de Norza-Céspedes, González-Rojas, Moscoso-Rojas y González Ramírez (2012, pág. 348), el porcentaje de madres cabeza de hogar en Colombia, frente al total de la población condenada femenina, ascendería al $84 \%$. restringidos), tienen mayores dificultades para acceder a programas de educación y trabajo, al no existir unos especialmente diseñados para ellas y sus necesidades. Como se ve, la situación de muchas madres con hijos en prisión es angustiosa, pues se debaten entre opciones imposibles: o bien dejan a sus hijos al cuidado de otros (muchas veces familiares lejanos o el Estado) con el temor de que sean maltratados o no sean cuidados adecuadamente y el remordimiento de sentir que los abandonaron; o bien los llevan con ellas a la cárcel, también sintiéndose culpables por hacerlos vivir en condiciones duras y privados de la libertad.

\section{B. El narcotráfico como delito de dominio femenino}

Otro tema común es el de la sobrerrepresentación de mujeres detenidas por narcotráfico, al punto que, de los delitos por los que se llega a la cárcel, este es de dominio femenino. Es decir que, aunque en términos absolutos haya más hombres que mujeres detenidos por narcotráfico, proporcionalmente es mayor el número de mujeres privadas de la libertad por este delito. Las mujeres sindicadas o condenadas por narcotráfico han aumentado notablemente durante las últimas dos décadas en todo el mundo y especialmente en América Latina. El alto número de mujeres detenidas por narcotráfico es un factor que explica, en buena medida, el aumento de la población reclusa femenina a nivel mundial durante las últimas dos décadas. En Colombia, el número de mujeres condenadas por narcotráfico ha aumentado un $206.6 \%$ durante la última década, mientras que el de los hombres 
se ha incrementado en un $187.3 \%$, una cifra de todas formas impresionante (Instituto Nacional Penitenciario y Carcelario [INPEC], 2013). ${ }^{3}$

En cuanto a la sobrerrepresentación de mujeres detenidas por narcotráfico en Colombia, el promedio de mujeres condenadas y sindicadas por narcotráfico, con respecto a toda la población reclusa femenina en los últimos diez años, ha sido del 30\% y el 16.3\%, respectivamente; el número total de sindicadas y condenadas por narcotráfico a enero de 2013, representa el $48.9 \%$ de toda la población interna femenina (INPEC, 2013). En otros países como Chile, Venezuela y Perú, el porcentaje de mujeres tras las rejas por delitos de narcotráfico ha llegado al $70 \%$ de toda la población reclusa femenina (Antony, 2000). ${ }^{4}$ En cambio, el promedio de hombres condenados y sindicados por narcotráfico durante los últimos diez años en Colombia ha sido 10.5\% y 5.5\%, respectivamente; a enero de 2013, los sindicados y condenados por este delito representaban un $17.8 \%$ del total (INPEC, 2013).

La interpretación predominante que se ha dado a esta situación en América Latina es que las mujeres que terminan en la cárcel por delitos relacionados con narcotráfico: participan en las escalas inferiores del tráfico y venta de drogas ilícitas - principalmente como mulas y expende-

3 Igualmente, para el caso colombiano, ver Uprimny y Guzmán (2010). Para el caso español, ver Almeda (2005).

4 Entre 2003 y 2004 , el $49 \%$ de las mujeres presas en Argentina lo estaban por narcotráfico; en Costa Rica el $66 \%$; en Colombia el $47 \%$; en Ecuador el $73 \%$; en El Salvador el $46 \%$; en Guatemala el 26\%; en Honduras el 59\%; en Nicaragua el $89 \%$; en Panamá el $72 \%$; en Perú el $56 \%$; en República Dominicana el 50\%; en Venezuela el $64 \%$ (CELS et al., 2011, pág. 1). doras-, suelen estar en condición de pobreza y exclusión, son madres cabeza de familia con hijos pequeños o nietos a su cargo, las condiciones en que realizan dicha actividad -muchas veces desde el hogar- les permite obtener un sustento para ellas y sus hijos o nietos, al tiempo que no descuidan sus responsabilidades como madres, abuelas y amas de casa (Antony, 2007, pág. 77; Rodríguez, 2004, pág. 10; cels et al., 2011, pág. 11).

El endurecimiento de la política contra las drogas durante las últimas tres décadas ha dado lugar a que la prisión se convierta en la forma privilegiada de castigo y tratamiento de las mujeres que cometen este tipo de conductas. Esto sin mayor consideración sobre su condición de exclusión y en muchos casos de madres cabeza de familia, quienes, con poco acceso al mercado laboral formal, deben dedicarse a actividades informales y delictivas para sostener a sus hijos. La retórica punitivista las define como mujeres y madres irresponsables, quienes deben responder por sus actos. Y la prisión, con sus penas cada vez más largas y mayor restricción de beneficios judiciales (como otorgamiento de la libertad condicional o de penas y medidas de seguridad alternativas a la cárcel) es el lugar donde deben hacerlo.

\section{EL PERFIL DE LAS MUJERES PRESAS EN COLOMBIA}

Colombia no ha sido ajena ni al fenómeno del incremento del encarcelamiento de las mujeres durante las últimas dos décadas en América La- 
tina, ni tampoco a los análisis criminológicos y penales que, desde perspectivas de género, han dado cuenta del fenómeno. No obstante, este debate en Colombia sigue siendo incipiente pues la perspectiva de género y el padecimiento de las mujeres en las cárceles se diluyen en medio de problemas que parecen más urgentes, como el hacinamiento, pero que terminan por ser planteados desde las necesidades e intereses de los hombres reclusos; en Colombia, como en tantos otros países, la situación de las mujeres pasa a un segundo plano tanto en los discursos penal y criminológico como en los discursos oficiales y la política pública sobre prisiones.

Lo anterior se evidencia en las escasas e incompletas estadísticas que el Estado publica y usa sobre mujeres en prisión, aunque algo similar puede decirse de las cifras sobre hombres. ${ }^{5}$ Como se verá en las siguientes páginas, aunque hay información relevante sobre las mujeres detenidas, faltan muchos datos que resultan esenciales para construir un perfil completo de la población reclusa femenina y para que sea de utilidad para diseñar y aplicar políticas con enfoque diferencial que respondan a sus condi-

5 El encargado de recolectar, organizar y publicar las estadísticas penitenciarias y carcelarias es el Instituto Nacional Penitenciario y Carcelario (INPEC). Esta entidad las publica con regularidad en su página web. No obstante, no publica mucha información de la que obtiene a través de la Sistematización Integral del Sistema Penitenciario y Carcelario (SISIPEC), una base de datos que organiza la información de las internas desde el momento de su ingreso al establecimiento de reclusión hasta cuando quedan en libertad (ver, http://www.INPEC.gov.co/portal/page/ portal/Inpec/SeccionSisipec1/PaginaLogin). Tampoco incluye en la base de datos información que podría ser relevante para construir de forma más precisa el perfil socioeconómico de las internas, dato fundamental para comprender su contexto y trayectoria. Esta información es el punto de partida para estructurar una política pública razonable. De otra parte, acceder a la información que no ha sido publicada es muy difícil pues el INPEC la guarda con mucho cuidado alegando razones de seguridad. ciones y necesidades. Además, muchas de las cifras existentes ni siquiera se publican de forma sistemática y periódica, lo cual imposibilita hacer análisis detallados que evidencien cambios y tendencias a lo largo de una línea larga y continua de tiempo. ${ }^{6}$

Lo más sorprendente es que estas cifras podrían estar disponibles, pero los encargados del sistema penitenciario no se han dado a la tarea de recolectarlas, organizarlas y publicarlas de forma periódica y sistemática, con el fin de que sirvan de insumo para crear una política pública adecuada y de información que permita que la sociedad civil pueda ejercer veeduría y participar en el necesario cambio del sistema. El secretismo y opacidad del sistema penitenciario y carcelario, difícil de penetrar y observar, es una de sus características fundamentales. Los muros de la prisión no sirven solo para que las reclusas no escapen, sino para que la sociedad no pueda posar su mirada sobre ellas.

La invisibilización de las mujeres presas en Colombia, como lo evidencia gráficamente el caso de las estadísticas oficiales sobre ellas, también se refleja en las investigaciones y publicaciones sobre el tema. Aunque su número ha aumentado paulatinamente, especialmente las tesis de pregrado y maestría universitarias, los estudios sobre mujeres encarceladas, y la criminalidad femenina en general, siguen siendo escasos,

6 Por ejemplo, es usual que datos interesantes y básicos como el tipo de delitos más representativos en la cárcel, la duración de las penas de las condenadas o de detención preventiva de las sindicadas, existan solo para algunos años. Tampoco se publican ni se ponen a disposición del público cruces entre, por ejemplo, tipo de delitos por los que las personas se encuentran detenidas y duración de la condena o privación preventiva de la libertad con respecto a esos delitos. 
poco difundidos y producidos más que todo por entidades oficiales como la Defensoría del Pueblo, la Procuraduría General de la Nación, la Contraloría General de la República, antes que por la academia, organizaciones no gubernamentales o centros de investigación. ${ }^{7}$

En lo que sigue de esta sección analizaremos las principales estadísticas sobre mujeres reclusas. A pesar de sus limitaciones, resultan útiles para al menos ayudar a armar el rompecabezas de las mujeres que llegan a prisión, y aproximarnos un poco más a saber quiénes son, de dónde provienen, cuáles eran sus condiciones de vida antes de entrar en la cárcel, a qué se dedicaban, si tienen familia, si han sido sometidas a formas de violencia o discriminación, por qué delitos el Estado las encarcela, cuánto permanecen en prisión y qué hacen durante su encierro. En fin, aspectos importantes de conocer para tratar de entender quiénes son las encarceladas en nuestra sociedad y por qué; cómo trata la prisión a estas mujeres y cómo construyen su identidad; y, por lo tanto, el tratamiento que requieren, así como la intensidad y duración de este.

Con el fin de construir un perfil, al menos parcial, de las mujeres encarceladas en Colombia, en lo que sigue discutiremos datos -y sus variaciones y tendencias a lo largo de la última década-, como el número de mujeres sindicadas y condenadas y su proporción frente a los hom- bres; su grado de escolaridad; los delitos por los que están detenidas; la duración de sus condenas; su acceso a programas de resocialización; el número de mujeres gestantes y lactantes. Esta información permitirá evidenciar cómo la población reclusa femenina es muy distinta a la masculina, aunque compartan algunos rasgos, así como mostrar patrones interesantes, como el aumento desproporcionado de la población interna femenina frente a la masculina en los últimos años, la sobrerrepresentación de mujeres detenidas por narcotráfico en comparación con los hombres, datos que pueden dar luces sobre los aspectos principales que marcan el encierro de las mujeres y que pueden constituir factores de discriminación.

Estos datos también permiten establecer comparaciones con otros países, especialmente de América Latina, lo cual puede resultar interesante para identificar tendencias a nivel regional y lo que estas significan. El caso de las mujeres detenidas por narcotráfico es un buen ejemplo. Las cifras confirman que en Colombia, como en toda la región, las mujeres están detenidas de forma desproporcionada por delitos relacionados con el tráfico de drogas; es el delito por el que hay mayor número de detenidas y su porcentaje frente al total de la población femenina es mucho mayor que el de su contraparte masculina.

$7 \quad$ En el curso de esta investigación no se reunieron más de diez publicaciones especializadas en el tema de la criminalidad femenina o las mujeres reclusas en Colombia. Estos fueron: Norza-Céspedes et al. (2012), Vizcaíno (2010), Briceño-Donn (2006), Jimeno (2004), Caro (1991), Defensoría del Pueblo (2004), Observatorio de Convivencia y Seguridad Ciudadana (2007), Ramos (2004), Hernández (1947), Uprimny y Guzmán (2010). 
A. La población reclusa femenina: número de detenidas, situación jurídica e infraestructura disponible

Lo primero que se debe destacar sobre la población reclusa femenina en Colombia es su vertiginoso aumento durante las últimas dos décadas. Entre 1990 y 2013 aumentó un 329.3\% (pasó de 1.998 mujeres detenidas en 1990 a 8.579 en 2013) en comparación con un $249.7 \%$ de la población masculina (que también registró un aumento impresionante: de 30.389 hombres en 1990 ascendió a 106.293 en 2013) como se aprecia en la tabla 1. Durante este tiempo, la población masculina ha representado en promedio el 93\% del total de la población reclusa, mientras la femenina solo el $7 \%$.

Tabla 1. Población reclusa femenina y masculina 1990-2013 (enero)

\begin{tabular}{|c|c|c|c|c|c|}
\hline \multirow{3}{*}{$\begin{array}{l}\text { Año } \\
2013 \\
\end{array}$} & \multirow{2}{*}{\multicolumn{2}{|c|}{$\begin{array}{c}\text { Hombres } \\
\text { población/porcentaje }\end{array}$}} & \multirow{2}{*}{\multicolumn{2}{|c|}{$\begin{array}{c}\text { Mujeres } \\
\text { población/porcentaje }\end{array}$}} & \multirow{3}{*}{$\begin{array}{c}\text { Total } \\
114.872 \\
\end{array}$} \\
\hline & & & & & \\
\hline & 106.293 & $92,53 \%$ & 8.579 & $7,47 \%$ & \\
\hline 2012 & 105.387 & $92,54 \%$ & 8.497 & $7,46 \%$ & 113.884 \\
\hline 2011 & 92.968 & $92,55 \%$ & 7.483 & $7,45 \%$ & 100.451 \\
\hline 2010 & 78.760 & $93,27 \%$ & 5.684 & $6,73 \%$ & 84.444 \\
\hline 2009 & 71.204 & $93,70 \%$ & 4.788 & $6,30 \%$ & 75.992 \\
\hline 2008 & 65.786 & $94,01 \%$ & 4.193 & $5,99 \%$ & 69.979 \\
\hline 2007 & 59.980 & $94,30 \%$ & 3.632 & $5,71 \%$ & 63.603 \\
\hline 2006 & 56.626 & $94,34 \%$ & 3.389 & $5,65 \%$ & 60.021 \\
\hline 2005 & 62.707 & $93,83 \%$ & 4.122 & $6,17 \%$ & 66.829 \\
\hline 2004 & 63.385 & $93,19 \%$ & 4.635 & $6,81 \%$ & 68.020 \\
\hline 2003 & 58.098 & $93,29 \%$ & 4.179 & $6,71 \%$ & 62.277 \\
\hline 2002 & 49.606 & $93,71 \%$ & 3.330 & $6,29 \%$ & 52.936 \\
\hline 2001 & 46.142 & $93,59 \%$ & 3.160 & $6,41 \%$ & 49.302 \\
\hline 2000 & 48.377 & $93,90 \%$ & 3.141 & $6,10 \%$ & 51.518 \\
\hline 1999 & 42.434 & $94,16 \%$ & 2.630 & $5,84 \%$ & 45.064 \\
\hline 1998 & 41.639 & $93,79 \%$ & 2.759 & $6,21 \%$ & 44.398 \\
\hline 1997 & 39.508 & $94,00 \%$ & 2.520 & $6,00 \%$ & 42.028 \\
\hline 1996 & 37.163 & $93,67 \%$ & 2.513 & $6,33 \%$ & 39.676 \\
\hline 1995 & 31.689 & $95,28 \%$ & 1.569 & $4,72 \%$ & 33.258 \\
\hline 1994 & 27.526 & $93,92 \%$ & 1.817 & $6,20 \%$ & 29.308 \\
\hline 1993 & 27.344 & $93,92 \%$ & 1.770 & $6,08 \%$ & 29.114 \\
\hline 1992 & 25.622 & $93,80 \%$ & 1.694 & $6,20 \%$ & 27.316 \\
\hline 1991 & 24.709 & $93,42 \%$ & 1.741 & $6,58 \%$ & 26.450 \\
\hline 1990 & 30.389 & $93,83 \%$ & 1.998 & $6,17 \%$ & 32.387 \\
\hline
\end{tabular}

Elaboración propia. Fuente: INPEC. 
En cuanto a la relación entre sindicadas y condenadas, las estadísticas del INPEC no hacen esta diferenciación por género sino a partir de 2003. Entre 2003 y 2009 es notable cómo hay un porcentaje considerablemente mayor de mu- jeres sindicadas que de hombres sindicados; incluso en 2003 y 2004 hay más sindicadas que condenadas. Tal relación comienza a invertirse desde 2010 (ver tabla 2).

Tabla 2. Situación jurídica de mujeres y hombres recluidos 2003-2013 (enero)

\begin{tabular}{|c|c|c|c|c|c|c|c|c|}
\hline \multirow{2}{*}{ Año } & \multicolumn{4}{|c|}{ Hombres } & \multicolumn{4}{c|}{ Mujeres } \\
\cline { 2 - 9 } & \multicolumn{3}{|c|}{ Sindicados/Porcentaje } & \multicolumn{1}{|c|}{ Condenados/Porcentaje } & \multicolumn{3}{c|}{ Sindicadas/Porcentaje } & \multicolumn{2}{c|}{ Condenadas/Porcentaje } \\
\hline ene-13 & 33.000 & $31,05 \%$ & 73.293 & $68,95 \%$ & 2.519 & $29,36 \%$ & 6.060 & $70,64 \%$ \\
\hline 2012 & 32.114 & $30,47 \%$ & 73.273 & $69,53 \%$ & 2.457 & $28,92 \%$ & 6.040 & $71,08 \%$ \\
\hline 2011 & 25.394 & $27,31 \%$ & 67.574 & $72,69 \%$ & 1.926 & $25,74 \%$ & 5.557 & $74,26 \%$ \\
\hline 2010 & 24.356 & $30,92 \%$ & 54.404 & $69,08 \%$ & 1.560 & $27,45 \%$ & 4.124 & $72,55 \%$ \\
\hline 2009 & 22.749 & $31,95 \%$ & 48.455 & $68,05 \%$ & 1.820 & $38,01 \%$ & 2.968 & $61,99 \%$ \\
\hline 2008 & 22.392 & $34,04 \%$ & 43.394 & $65,96 \%$ & 1.663 & $39,66 \%$ & 2.530 & $60,34 \%$ \\
\hline 2007 & 20.701 & $34,51 \%$ & 39.279 & $65,49 \%$ & 1.482 & $40,80 \%$ & 2.150 & $59,20 \%$ \\
\hline 2006 & 17.987 & $31,76 \%$ & 38.639 & $68,24 \%$ & 1.360 & $40,13 \%$ & 2.029 & $59,87 \%$ \\
\hline 2005 & 23.898 & $38,11 \%$ & 38.809 & $61,89 \%$ & 1.851 & $44,91 \%$ & 2.271 & $55,09 \%$ \\
\hline 2004 & 26.438 & $41,71 \%$ & 36.947 & $58,29 \%$ & 2.373 & $51,20 \%$ & 2.262 & $48,80 \%$ \\
\hline 2003 & 24.286 & $41,80 \%$ & 33.812 & $58,20 \%$ & 2.111 & $50,51 \%$ & 2.068 & $49,49 \%$ \\
\hline
\end{tabular}

Elaboración propia. Fuente: INPEC.

Una de las críticas más comunes a la situación de las mujeres en prisión es la falta de adecuación de la infraestructura carcelaria para responder a las necesidades del género femenino. Esto parece constatarse claramente en Colombia. De un total de 141 centros de reclusión a cargo del INPEC, solo existen 6 reclusiones de mujeres (en Bogotá, Popayán, Bucaramanga, Manizales, Armenia y Pereira) que albergan a 3.747 (de un total de 8.814 a marzo de 2013). En otros 37 centros de reclusión, las mujeres aunque estén en pabellones separados comparten espacio y servicios con los hombres, quienes en todos los casos son un número considerablemente mayor. Al ser una minoría en todos estos penales, existe una alta probabilidad de que las mujeres se encuentren en situación de desventaja frente a los hombres para tener acceso a espacios y servicios adecuados, así como a programas de resocialización.

Las seis reclusiones de mujeres, por su número tan reducido, albergan a casi la mitad de la población reclusa femenina $(42,5 \%)$ y en consecuencia tienen altos índices de hacinamiento, un promedio del $86 \%$, lo cual supera ampliamente el promedio de todos los establecimientos de reclusión, que en marzo de 2013 llegó al $53,7 \% .{ }^{8}$ Por consiguiente, puede afirmarse que

8 En la reclusión de mujeres El Buen Pastor de Bogotá, donde se realizó el trabajo de campo para esta investigación, el hacinamiento es 
la limitada infraestructura para albergar mujeres hace que se deban concentrar en menos centros de reclusión y que deban padecer más altos índices de hacinamiento que los hombres, aunque varios centros de reclusión masculinos también presentan este mismo problema.

\section{B. Edad, nivel educativo, entorno familiar y social}

Con respecto a la edad de la población reclusa solo hay información disponible entre 1999 y 2012. Tanto entre hombres como entre mujeres prevalece una población joven, aunque la tendencia es más marcada entre los hombres; en el rango entre 18 y 29 años el porcentaje de hombres es mayor que el de mujeres todos los años (desde 2002 constituye el rango con más alto porcentaje dentro de la población masculina). En cambio, a pesar de que también existe un alto porcentaje de mujeres recluidas dentro del rango de 18 a 29 años (un promedio del $36,3 \%$ frente a un promedio del $41,3 \%$ para los hombres entre 1999 y 2012), la mayor cantidad de mujeres presas se encuentra dentro del rango de 30 a 54 años, con un promedio del 37,3\% frente al total de reclusas ${ }^{9}$ (ver tabla 3 ). Estas cifras pueden indicar que los hombres se involucran en actividades delictivas antes que las mujeres, por lo que tienen mayores probabilidades

del 74,7\%; en Popayán es del 118\%; en Bucaramanga, del 113\%; en Manizales, del $62 \%$; en Armenia, del $88 \%$ y en Pereira, del $61 \%$ (INPEC, 2013).

9 Los hombres en este rango de edad constituyen el $36 \%$ de la población masculina. de ser encarcelados a edad más temprana que ellas. ${ }^{10}$

Esto también parece confirmar una afirmación recurrente de la literatura feminista: Ias mujeres tienden a retrasar su encuentro con la ley penal pues están sometidas a otras formas de control social que las alejan de actividades delictivas, al menos por un tiempo. Las labores domésticas, la maternidad, hacen que muchas mujeres permanezcan más tiempo en el hogar, bajo distintas miradas disciplinarias, y que se reduzcan los factores de riesgo que pueden llevarlas a cometer delitos, como por ejemplo la asociación con otras personas, generalmente grupos de amigos, que ya han incurrido en actividades delictivas. Esto, a su vez, explica por qué proporcionalmente hay más mujeres que hombres en el rango de 30 a 54 años. Muchas mujeres inician más tarde que los hombres actividades delictivas porque la situación de pobreza y exclusión en que se encuentran, acompañadas muchas veces del deber de proveer lo necesario para hijos o nietos, hacen que encuentren en dichas actividades, particularmente las relacionadas con microtráfico de estupefacientes, ${ }^{11}$ una fuente de ingresos que garantice su sustento y el de sus familias.

10 No obstante, el estudio de Norza-Céspedes et al. (2012, pág. 349) indica que las mujeres recluidas también comenzaron sus actividades delictivas a temprana edad; más de la mitad lo hizo antes de los 25 años de edad; el 13\% manifestó haber estado recluida alguna vez en una correccional de menores, y el $67 \%$ indicó ser reincidente.

11 Sería interesante hacer cruces entre los rangos de edad de las mujeres detenidas y los delitos por los que están sindicadas y condenadas. Sin embargo, el INPEC no publica este tipo de información donde se relacionan variables claves. 
Tabla 3. Rangos de edad de mujeres y hombres privados de la libertad (1999-2012)

\begin{tabular}{|c|c|c|c|c|c|c|c|c|}
\hline \multirow{2}{*}{ Año } & \multicolumn{2}{|c|}{$\mathbf{1 8}$ a 29 Años } & \multicolumn{2}{c|}{30 a 54 Años } & \multicolumn{2}{c|}{ 55 a 64 Años } & \multicolumn{2}{c|}{ Mayor a 64 Años } \\
\cline { 2 - 9 } & Hombre & Mujer & Hombre & Mujer & Hombre & Mujer & Hombre & Mujer \\
\hline 2012 & $43,0 \%$ & $38,4 \%$ & $47,6 \%$ & $55,7 \%$ & $4,1 \%$ & $5,1 \%$ & $1,4 \%$ & $0,8 \%$ \\
\hline 2011 & $43,3 \%$ & $38,6 \%$ & $47,6 \%$ & $55,8 \%$ & $3,9 \%$ & $4,9 \%$ & $1,3 \%$ & $0,7 \%$ \\
\hline 2010 & $45,9 \%$ & $40,7 \%$ & $35,7 \%$ & $39,8 \%$ & $12,5 \%$ & $16,7 \%$ & $3,4 \%$ & $2,7 \%$ \\
\hline 2009 & $46,7 \%$ & $42,4 \%$ & $34,9 \%$ & $39,7 \%$ & $12,8 \%$ & $16,1 \%$ & $3,2 \%$ & $1,8 \%$ \\
\hline 2008 & $46,7 \%$ & $40,2 \%$ & $34,4 \%$ & $40,9 \%$ & $13,5 \%$ & $17,0 \%$ & $3,2 \%$ & $1,9 \%$ \\
\hline 2007 & $46,3 \%$ & $43,2 \%$ & $35,6 \%$ & $40,1 \%$ & $13,2 \%$ & $15,1 \%$ & $2,7 \%$ & $1,7 \%$ \\
\hline 2006 & $46,7 \%$ & $40,4 \%$ & $35,2 \%$ & $40,4 \%$ & $13,7 \%$ & $17,3 \%$ & $2,2 \%$ & $1,9 \%$ \\
\hline 2005 & $45,5 \%$ & $41,1 \%$ & $36,1 \%$ & $40,0 \%$ & $14,0 \%$ & $16,7 \%$ & $2,0 \%$ & $2,2 \%$ \\
\hline 2004 & $46,9 \%$ & $41,0 \%$ & $33,9 \%$ & $39,8 \%$ & $14,2 \%$ & $17,8 \%$ & $2,5 \%$ & $1,4 \%$ \\
\hline 2003 & $49,5 \%$ & $43,7 \%$ & $34,1 \%$ & $39,9 \%$ & $12,1 \%$ & $14,6 \%$ & $1,8 \%$ & $1,7 \%$ \\
\hline 2002 & $35,9 \%$ & $32,6 \%$ & $34,0 \%$ & $33,5 \%$ & $10,1 \%$ & $11,5 \%$ & $2,1 \%$ & $1,8 \%$ \\
\hline 2001 & $29,8 \%$ & $28,2 \%$ & $33,9 \%$ & $24,7 \%$ & $9,5 \%$ & $10,8 \%$ & $2,0 \%$ & $2,4 \%$ \\
\hline 2000 & $29,0 \%$ & $22,7 \%$ & $33,3 \%$ & $20,9 \%$ & $8,6 \%$ & $9,5 \%$ & $2,0 \%$ & $2,1 \%$ \\
\hline 1999 & $22,5 \%$ & $14,4 \%$ & $28,6 \%$ & $11,7 \%$ & $7,0 \%$ & $6,7 \%$ & $2,3 \%$ & $2,4 \%$ \\
\hline
\end{tabular}

Elaboración propia. Fuente: INPEC.

Además de ser joven, la población reclusa en Colombia presenta bajos niveles educativos. A enero de 2013 , el $89,87 \%$ de la población femenina no ha terminado el bachillerato; el 37.7\% no ha terminado primaria y el 52,17\% completó primaria pero no terminó bachillerato. Los bajos niveles educativos de las mujeres son muy similares a los de los hombres; el 91,56\% no ha completado el bachillerato; de estos, 39,11\% no terminó primaria y el 52,43\% culminó primaria pero no bachillerato. El $4,28 \%$ de las mujeres y el $5,47 \%$ de los hombres son analfabetas (ver tabla 4).

Lo anterior quiere decir que solo el 5,85\% de las mujeres y el 2,7\% de los hombres privados de la libertad terminaron el bachillerato. Semejantes tasas de deserción escolar son un factor explicativo de por qué las personas que terminan en la cárcel tienen mayores dificultades para acceder a empleos formales: no cuentan con las cualificaciones mínimas para ser admitidas en el mercado laboral. Este es un aspecto importante a la hora de explicar los motivos por los que las mujeres encarceladas, dada su condición económica y social ${ }^{12}$ y su rol de mujeres y madres, decidieron realizar conductas delictivas. 
Tabla 4. Niveles educativos de la población reclusa (2010-2013)

\begin{tabular}{|c|c|c|c|c|}
\hline \multirow[t]{2}{*}{ Año } & \multicolumn{2}{|c|}{ No. reclusos } & \multicolumn{2}{|c|}{ No. reclusas } \\
\hline & \multicolumn{2}{|c|}{ población /porcentaje } & \multicolumn{2}{|c|}{ población /porcentaje } \\
\hline \multicolumn{5}{|c|}{ Iletradas } \\
\hline 2010 & 4.491 & $5,70 \%$ & 267 & $4,70 \%$ \\
\hline 2012 & 5.733 & $5,44 \%$ & 358 & $4,21 \%$ \\
\hline ene-13 & 5.811 & $5,47 \%$ & 367 & $4,28 \%$ \\
\hline \multicolumn{5}{|c|}{ Grado 1-2-3 } \\
\hline 2010 & 13.492 & $17,13 \%$ & 963 & $16,94 \%$ \\
\hline 2012 & 16.805 & $15,95 \%$ & 1.289 & $15,17 \%$ \\
\hline ene-13 & 16.936 & $15,93 \%$ & 1.308 & $15,25 \%$ \\
\hline \multicolumn{5}{|c|}{ Grado 4-5 } \\
\hline 2010 & 19.140 & $24,30 \%$ & 1.449 & $25,49 \%$ \\
\hline 2012 & 24.396 & $23,15 \%$ & 1.926 & $22,67 \%$ \\
\hline ene-13 & 24.640 & $23,18 \%$ & 1.927 & $22,46 \%$ \\
\hline \multicolumn{5}{|c|}{ Grado 6-7 } \\
\hline 2010 & 12.602 & $16,00 \%$ & 870 & $15,31 \%$ \\
\hline 2012 & 16.972 & $16,10 \%$ & 1.302 & $15,32 \%$ \\
\hline ene-13 & 17.183 & $16,17 \%$ & 1.328 & $15,48 \%$ \\
\hline \multicolumn{5}{|c|}{ Grado 8-9 } \\
\hline 2010 & 10.850 & $13,78 \%$ & 811 & $14,27 \%$ \\
\hline 2012 & 15.199 & $14,42 \%$ & 1.250 & $14,71 \%$ \\
\hline ene-13 & 15.379 & $14,47 \%$ & 1.265 & $14,75 \%$ \\
\hline \multicolumn{5}{|c|}{ Grado 10} \\
\hline 2010 & 3.344 & $4,25 \%$ & 232 & $3,10 \%$ \\
\hline 2012 & 4.966 & $4,71 \%$ & 418 & $4,92 \%$ \\
\hline ene-13 & 5.021 & $4,72 \%$ & 407 & $4,74 \%$ \\
\hline \multicolumn{5}{|c|}{ Grado 11} \\
\hline 2010 & 12.452 & $15,81 \%$ & 963 & $16,94 \%$ \\
\hline 2012 & 17.962 & $17,04 \%$ & 1.444 & $16,99 \%$ \\
\hline ene-13 & 18.169 & $17,09 \%$ & 1.476 & $17,20 \%$ \\
\hline
\end{tabular}

Elaboración propia. Fuente: INPEC.

En cuanto a la situación familiar de las reclusas, tiene sobre ellas y su entorno familiar, y el tipo como se indicó antes, las cifras disponibles son de tratamiento y servicios que requieren. Según muy escasas, a pesar de la trascendencia del la Procuraduría Delegada en lo Preventivo para tema para entender las razones por las que las Derechos Humanos y Asuntos Étnicos General mujeres Ilegan a la cárcel, el impacto que esta de la Nación (2006, pág. 30), el 53.1\% de las 
mujeres privadas de la libertad eran cabeza de familia, y la mayoría tenían hijos menores de edad, entre los 4 y los 10 años. Una de las poblaciones más vulnerables dentro de la prisión es la conformada por las mujeres gestantes, lactantes y con hijos menores de 3 años de edad, quienes están privados de la libertad con ellas. En este aspecto los datos del INPEC también son bastante incompletos; solo hay información disponible entre los años 2003 y 2011.

Aunque son una minoría, que además ha tendido a disminuir en los últimos años, ${ }^{13}$ este grupo de madres no deja de ser una parte significativa de la población reclusa: representa un 3,81\% de esta (ver tabla 5). Esta población tiene necesidades especiales de atención médica y asistencia social (como guarderías, salud, alimentación y educación para sus hijos) que no se ven adecuadamente satisfechas dada la precariedad y falta de cobertura de los servicios que presta la cárcel. Así, los hijos de las internas terminan por padecer con ellas el rigor de los castigos que les son impuestos, lo cual puede tener un impacto negativo en su desarrollo y bienestar a mediano y largo plazo.

Tabla 5. Madres con hijos, madres lactantes y madres gestantes en prisión (2003-2011)

\begin{tabular}{|c|c|c|c|c|c|}
\hline Año & $\begin{array}{c}\text { Madres con hijos } \\
\text { en prisión }\end{array}$ & Madres lactantes & Madres gestantes & Total & Porcentaje \\
\hline 2011 & Sin inf. & 25 & 62 & 87 & $1,16 \%$ \\
\hline 2010 & 84 & 23 & 52 & 159 & $2,79 \%$ \\
\hline 2009 & 84 & 23 & 73 & 180 & $3,75 \%$ \\
\hline 2008 & 86 & 29 & 78 & 193 & $4,60 \%$ \\
\hline 2007 & 76 & 22 & 48 & 146 & $4,01 \%$ \\
\hline 2006 & 86 & 24 & 50 & 160 & $4,72 \%$ \\
\hline 2005 & 95 & 52 & 85 & 232 & $5,62 \%$ \\
\hline 2004 & 106 & Sin inf. & Sin inf. & Sin inf. & Sin inf. \\
\hline 2003 & 101 & Sin inf. & Sin inf. & Sin inf. & Sin inf. \\
\hline
\end{tabular}

Elaboración propia. Fuente: INPEC.

Norza-Céspedes et al. (2012, pág. 350) indican que el $90 \%$ de las mujeres condenadas en cuatro centros de reclusión del país (Bogotá, MedeIlín, Cali y Cúcuta), que representan el 10\% de la población femenina condenada, son madres y, de ellas, el $85 \%$ es cabeza de hogar. El 51,6\%

13 Probablemente porque desde 2004 la ley penal (artículo 314 de la Ley 906 de 2004) permite que se les sustituya la privación de la libertad en centro de reclusión por detención o prisión domiciliaria. tuvo su primer hijo cuando era menor de edad; el 53\% manifiesta haber sufrido en sus hogares, en algún momento de sus vidas, la presencia de alcoholismo, drogadicción, violencia intrafamiliar o sexual; el 11\% alguna vez estuvo a cargo del Instituto Colombiano de Bienestar Familiar, lo que indica maltrato o abandono de sus padres; el 35,8\% afirma haber sido maltratado durante la infancia y el $78,7 \%$ haber sido víctima 
de alguna forma de abuso físico o sexual; el $42 \%$ dijo haber cometido conductas ilegales por falta de empleo y recursos suficientes para subsistir o sostener a sus hijos; el $45 \%$ tiene algún familiar que cometió uno o más delitos; el 44\% consumió drogas alguna vez y el $20 \%$ consume de forma regular alcohol o sustancias psicoactivas.

A pesar de que las anteriores cifras son apenas una muestra del total de la población reclusa femenina, por lo que hay que ser cautos en las conclusiones que se deriven de ellas, son un indicador claro de la situación de vulnerabilidad, exclusión y violencia a la que se ha visto sometida buena parte de las mujeres que terminan en prisión. Por esto, su entorno social y familiar son aspectos claves para entender los motivos y factores asociados a sus conductas delictivas, así como el impacto que la prisión puede tener sobre ellas y su entorno familiar, incluso aumentando las condiciones de riesgo y discriminación a que se han visto expuestas. El más claro ejemplo de esto es el efecto desestructurador que la prisión tiene sobre las familias, especialmente sobre los hijos de las reclusas, el cual no hace sino empeorar condiciones de vida de por sí muy precarias. El silencio de las cifras oficiales en este aspecto evidencia la indiferencia del sistema penitenciario frente a las características y necesidades de la población que debe atender, supuestamente, para proveerle un tratamiento resocializador adecuado.

\section{Delitos, tiempos de condena y acceso a actividades de resocialización}

En cuanto a los delitos por los que hay más mujeres sindicadas y condenadas en las prisiones colombianas, no es sorprendente que el primer lugar lo ocupen los delitos relacionados con narcotráfico, que son de predominio femenino. A enero de 2013 el 42,39\% de las mujeres en detención preventiva estaban acusadas de narcotráfico; el 51,6\% estaban condenadas por este delito. Prácticamente la mitad (48,9\%) de la población reclusa femenina está detenida por actividades relacionadas con el narcotráfico. En contraste, los hombres sindicados por narcotráfico constituyen el $15,51 \% \%$ de la población sindicada masculina, mientras que los condenados representan el $18,92 \%$ de la población condenada. Los hombres privados de la libertad por delitos relacionados con narcotráfico constituyen el $17,86 \%$ de toda la población reclusa masculina. Este delito ocupa el cuarto lugar entre los delitos por los que hay más hombres privados de la libertad (ver tabla 6 ).

Como se ha mencionado a lo largo de este texto, proporcionalmente, quienes más van a prisión por delitos de narcotráfico son las mujeres, a pesar de que ocupan los lugares más bajos de la cadena (principalmente como mulas y expendedoras) y no suelen estar involucradas con crimen organizado o acciones violentas. Más bien lo que destaca es su pobreza y situación de exclusión antes de entrar a prisión; estas mujeres incurren en conductas relacionadas con narcotráfico no para enriquecerse de forma rápida, sino como una forma de subsistencia, para ellas 
y sus hijos, en condiciones muy precarias $^{14}$. Colombia, por tanto, confirma la tendencia mundial en cuanto a la sobrerrepresentación de las mujeres privadas de la libertad por tráfico de drogas.

Tabla 6. Principales delitos de la población reclusa (enero 2013)

\begin{tabular}{|c|c|c|c|}
\hline Tipo de delito & Sindicados & Tipo de delito & Sindicadas \\
\hline Hurto & $25,71 \%$ & $\begin{array}{l}\text { Tráfico, fabricación o porte de } \\
\text { estupefacientes }\end{array}$ & $42,40 \%$ \\
\hline $\begin{array}{l}\text { Fabricación, tráfico y porte de } \\
\text { armas de fuego o municiones }\end{array}$ & $22,12 \%$ & Hurto & $18,58 \%$ \\
\hline Homicidio & $18,64 \%$ & Concierto para delinquir & $13,93 \%$ \\
\hline $\begin{array}{l}\text { Tráfico, fabricación o porte de } \\
\text { estupefacientes }\end{array}$ & $15,52 \%$ & $\begin{array}{l}\text { Fabricación, tráfico y porte de } \\
\text { armas de fuego o municiones }\end{array}$ & $10,64 \%$ \\
\hline Concierto para delinquir & $12,67 \%$ & Homicidio & $10,32 \%$ \\
\hline Delitos sexuales & $9,11 \%$ & Secuestro extorsivo & $2,02 \%$ \\
\hline Tipo de delito & Condenados & Tipo de delito & Condenadas \\
\hline Hurto & $29,14 \%$ & $\begin{array}{l}\text { Tráfico, fabricación o porte de } \\
\text { estupefacientes }\end{array}$ & $51,62 \%$ \\
\hline Homicidio & $28,96 \%$ & Hurto & $19,27 \%$ \\
\hline $\begin{array}{l}\text { Fabricación, tráfico y porte de } \\
\text { armas de fuego o municiones }\end{array}$ & $22,43 \%$ & Homicidio & $11,49 \%$ \\
\hline $\begin{array}{l}\text { Tráfico, fabricación o porte de } \\
\text { estupefacientes }\end{array}$ & $18,92 \%$ & Concierto para delinquir & $6,60 \%$ \\
\hline Delitos sexuales & $9,29 \%$ & $\begin{array}{l}\text { Fabricación, tráfico y porte de } \\
\text { armas de fuego o municiones }\end{array}$ & $6,50 \%$ \\
\hline Concierto para delinquir & $7,33 \%$ & Secuestro extorsivo & $3,25 \%$ \\
\hline
\end{tabular}

Elaboración propia. Fuente: INPEC.

El segundo delito por el que hay más mujeres condenadas es el hurto, que representa el $19,27 \%$ del total. En el caso de los hombres condenados, este ocupa el primer lugar con el $29,14 \%$. Sigue el homicidio, con el $11,49 \%$ de mujeres condenadas por este delito, frente a un $28,96 \%$ de los hombres, ocupando el segundo

14 Las tres mujeres condenadas por narcotráfico que fueron entrevistadas para esta investigación, reclusas en El Buen Pastor, vivían o han vivido en condiciones de pobreza, sin empleo, dos de ellas son madres, y la otra incluso es una abuela cabeza de familia. lugar entre la población masculina condenada (ver tabla 6).

A enero de 2013, el rango de años de condena impuesta predominante entre las mujeres es de 0 a 5 años; el 59,4\% de la población condenada femenina se encuentra en este rango (por $41,4 \%$ de los hombres). El siguiente rango predominante entre las mujeres es el de 6 a 10 años de condena, con el 23,4\% del total (por un 
$25,3 \%$ de los hombres). El $82,8 \%$ de las mujeres no supera los 10 años de condena (por un $66,7 \%$ de los hombres). Lo anterior indica de forma clara que las mujeres pagan condenas más cortas que los hombres, tendencia que se comprueba a medida que aumentan los rangos de condena: en cada rango es mayor la presencia de los hombres que la de las mujeres (ver tabla 7). Los bajos rangos de años de condena de las mujeres, unidos a la predominancia del narcotráfico como el delito por el que hay más condenadas, permite concluir que la mayoría de mujeres en prisión se encuentra pagando penas relativamente cortas por delitos de narcotráfico. Esto implica a su vez la participación de las mujeres en los eslabones más bajos del tráfico de drogas (principalmente como mulas y expendedoras en redes de microtráfico), de lo cual derivan su sustento.

Tabla 7. Rangos de años de condena impuesta a la población reclusa (2010-enero 2013)

\begin{tabular}{|c|r|r|r|r|r|r|r|r|}
\hline \multirow{2}{*}{ Año } & \multicolumn{2}{|c|}{ O A 5 AÑOS } & \multicolumn{2}{c|}{ 6 A 10 AÑOS } & \multicolumn{2}{|c|}{ 11 A 15 AÑOS } & \multicolumn{2}{|c|}{ 16 A 20 AÑOS } \\
\cline { 2 - 9 } & Hombre & Mujer & Hombre & Mujer & Hombre & Mujer & Hombre & Mujer \\
\hline 2013 & $41,4 \%$ & $59,4 \%$ & $25,3 \%$ & $23,4 \%$ & $10,2 \%$ & $4,8 \%$ & $8,8 \%$ & $3,8 \%$ \\
2012 & $41,7 \%$ & $60,2 \%$ & $25,1 \%$ & $23,1 \%$ & $10,1 \%$ & $4,8 \%$ & $8,7 \%$ & $3,7 \%$ \\
\cline { 2 - 6 } 2010 & $46,3 \%$ & $65,2 \%$ & $22,6 \%$ & $15,8 \%$ & $11,0 \%$ & $5,5 \%$ & $8,7 \%$ & $4,3 \%$ \\
\hline
\end{tabular}

\begin{tabular}{|l|r|r|r|r|r|r|r|r|}
\hline \multirow{2}{*}{ Año } & \multicolumn{2}{|c|}{ 21 A 25 AÑOS } & \multicolumn{2}{|c|}{ 26 A 30 AÑOS } & \multicolumn{2}{|c|}{ 31 A 35 AÑOS } & \multicolumn{2}{|c|}{$\begin{array}{c}\text { MÁs DE 36 } \\
\text { AÑOS }\end{array}$} \\
\hline & Hombre & Mujer & Hombre & Mujer & Hombre & Mujer & Hombre & Mujer \\
\hline 2013 & $4,3 \%$ & $2,4 \%$ & $4,3 \%$ & $2,4 \%$ & $2,3 \%$ & $1,3 \%$ & $3,5 \%$ & $1,5 \%$ \\
\hline 2012 & $4,3 \%$ & $2,4 \%$ & $4,3 \%$ & $2,4 \%$ & $2,3 \%$ & $1,3 \%$ & $3,5 \%$ & $1,5 \%$ \\
\hline 2010 & $4,9 \%$ & $3,1 \%$ & $5,6 \%$ & $3,3 \%$ & $2,7 \%$ & $1,5 \%$ & $3,4 \%$ & $1,5 \%$ \\
\hline
\end{tabular}

Elaboración propia. Fuente: INPEC.

Finalmente, en lo referente a la participación de las mujeres en actividades de resocialización, cabe decir que para enero de 2013 era proporcionalmente mayor, aunque de forma ligera, a la de los hombres. El 33\% de las mujeres reclui- das participan en actividades de trabajo (frente al $25,5 \%$ de los hombres); el $34 \%$ en estudio (frente al $31 \%$ de los hombres); y el 1,38\% en actividades de enseñanza (frente al $1 \%$ de los hombres) (ver tabla 8). 
Tabla 8. Participación en actividades de resocialización de la población reclusa (2010- enero 2013)

\begin{tabular}{|c|c|c|c|c|c|c|c|c|c|c|c|c|}
\hline \multirow{3}{*}{$\begin{array}{c}\text { Año } \\
\text { ene-13 }\end{array}$} & \multicolumn{4}{|c|}{ Trabajo } & \multicolumn{4}{|c|}{ Estudio } & \multicolumn{4}{|c|}{ Enseñanza } \\
\hline & \multicolumn{2}{|c|}{ Hombres } & \multicolumn{2}{|c|}{ Mujeres } & \multicolumn{2}{|c|}{ Hombres } & \multicolumn{2}{|c|}{ Mujeres } & \multicolumn{2}{|c|}{ Hombres } & \multicolumn{2}{|c|}{ Mujeres } \\
\hline & 27118 & $25.5 \%$ & 2842 & $33 \%$ & 33073 & $31 \%$ & 2920 & $34 \%$ & 1081 & $1 \%$ & 119 & $1.38 \%$ \\
\hline 2012 & 28739 & $34.9 \%$ & 2967 & $27.2 \%$ & 34908 & $33 \%$ & 3134 & $36.8 \%$ & 1083 & $1 \%$ & 135 & $1.6 \%$ \\
\hline 2010 & 23536 & $32.6 \%$ & 1853 & $29.8 \%$ & 26360 & $33.4 \%$ & 2222 & $39 \%$ & 929 & $1.2 \%$ & 104 & $1.8 \%$ \\
\hline
\end{tabular}

Elaboración propia. Fuente: INPEC.

Las actividades laborales que el sistema penitenciario colombiano asigna a las mujeres corroboran las críticas que se han hecho a este tipo de programas. El tipo de actividades que se realiza no responde a las actitudes e inclinaciones de las mujeres (habida cuenta de las habilidades que podrían tener antes de ingresar a prisión) ni a sus necesidades para integrarse al mercado laboral una vez salgan libres. Las actividades que se asignan responden al imaginario tradicional sobre las labores que corresponden a las mujeres para cumplir su rol de género: labores domésticas y artesanales básicas como cocina, repostería y panadería; tejidos, bisutería, confecciones, lencería y bordados. A manera de ejemplo, el centro de reclusión de mujeres El Buen Pastor de Bogotá, donde se realizó el trabajo de campo de esta investigación, en las actividades de productividad artesanal hace énfasis en labores que pueden ser consideradas femeninas teniendo en cuenta su relación con el espacio futuro en el cual se pueden desempeñar -el hogar-y su relación con la función reproductiva asignada al espacio doméstico (ver tabla 9).

Tabla 9. Actividades de productividad artesanal en el centro de reclusión de mujeres El Buen Pastor de Bogotá (2013)

\begin{tabular}{|l|c|c|c|}
\hline \multicolumn{1}{|c|}{ Actividad } & $\begin{array}{c}\text { Cupo máx- } \\
\text { imo }\end{array}$ & $\begin{array}{c}\text { Cupo ac- } \\
\text { tual }\end{array}$ & Cupo disponible \\
\hline Bisutería & 35 & 31 & 4 \\
\hline $\begin{array}{l}\text { Manejo de fibras y materiales } \\
\text { naturales y sintéticos }\end{array}$ & 80 & 58 & 22 \\
\hline Lencerías y bordados & 23 & 18 & 5 \\
\hline Maderas & 30 & 28 & 2 \\
\hline Marroquinería & 15 & 8 & 7 \\
\hline Papel & 0 & 0 & 0 \\
\hline Telares y tejidos & 40 & 30 & 10 \\
\hline TOTAL & 223 & 173 & 59 \\
\hline
\end{tabular}

Elaboración propia. Fuente: INPEC-Centro de reclusión para mujeres El Buen Pastor. 


\section{CONCLUSIONES}

Uno de los principales retos que se plantean al analizar el fenómeno del encarcelamiento femenino es identificar sus aspectos diferenciales en relación con los diagnósticos existentes sobre el predominio de la experiencia penitenciaria femenina. En este trabajo hemos intentado avanzar en esta dirección, tratando de describir algunas particularidades de la experiencia penitenciaria de las mujeres en el contexto local y regional.

Así, el primero de ellos podría ser la invisibilización política del castigo penitenciario aplicado a las mujeres, a pesar de su creciente importancia. Aunque en términos absolutos el número de mujeres privadas de la libertad sea una fracción, que muchos considerarían insignificante con respecto al de los hombres, esta cifra es engañosa y no refleja la experiencia del castigo de las mujeres y sus diferencias relevantes frente a la población masculina. De hecho se ha convertido en un mecanismo de invisibilización material y simbólica de la condición de las mujeres presas y de su notable incremento en las últimas décadas, particularmente con respecto al delito de narcotráfico. Como se vio, el aumento de la población reclusa femenina ha sido proporcionalmente mayor al incremento de la población masculina en las últimas tres décadas. Y en cuanto a la participación en los delitos, es notable la sobrerrepresentación de mujeres privadas de la libertad, sindicadas o condenadas por narcotráfico, con respecto a los hombres. De lo anterior se puede concluir que en las pri- siones, el delito del narcotráfico por el cual se encuentra detenida una persona, es de dominio femenino. Y esta tendencia no es solo colombiana o latinoamericana, sino mundial.

En segundo lugar, además de las cifras de por sí dicientes, que evidencian la invisibilización de la condición femenina en el mundo social del encierro, creemos que un factor diferencial adicional se encuentra, precisamente, en la aplicación de los programas generales propios de una institución pensada para el delincuente masculino y no para la mujer que entra en conflicto con la ley penal. La política penitenciaria, por precaria que sea, se diseña con base en una concepción masculina del encierro. La infraestructura carcelaria, las formas y condiciones de seguridad, el régimen disciplinario, los programas de resocialización, los servicios que se prestan, son todos concebidos con base en un sujeto de rasgos masculinos. Por ello, aspectos como los anteriores, al ignorar o adaptar pobremente las necesidades y derechos de las mujeres frente al encierro, se convierten en mecanismos de discriminación o de intensificación injustificada del castigo. El Estado no toma en serio la perspectiva de género en la concepción y aplicación de las políticas criminal y penitenciaria, y mucho menos la importancia de pensar en estos términos, con el objetivo de poner fin a una tendencia global y creciente que lleva a que las mujeres pobres, jóvenes, muchas de ellas madres o hijas cabeza de familia, tiendan a ser desproporcionadamente criminalizadas y castigadas. Si bien resulta problemático -desde el punto de vista político y teórico- maternalizar la experiencia penitenciaria femenina, y asimilar la 
situación de mujer madre presa a la condición general de las mujeres privadas de la libertad, parece que el discurso institucional actual que intenta asumir un enfoque diferencial considera que, precisamente, la maternidad, y definir a la mujer presa en relación son sus roles reproductivos, es el factor clave de esta nueva sensibilidad penitenciaria.

Por último, y estrechamente relacionado con lo anterior, estos factores se conectan con un problema social complejo que varias autoras latinoamericanas han explicado, como es la feminización de la pobreza. En el ámbito del castigo, como en otros campos sociales, se constata cómo el hecho de ser mujer, pobre y excluida social y económicamente hace más probable el castigo e intensifica su sufrimiento y consecuencias, tanto para las mujeres como para sus seres cercanos, particularmente para sus hijos. De hecho, la cárceles se convierten para varias mujeres en una etapa más en una trayectoria marcada por la discriminación, la exclusión y distintas formas de violencia y abuso, que a su vez las pueden llevar a tener contacto con el consumo de drogas y la criminalidad.

La sobrerrepresentación de las mujeres detenidas por el delito de narcotráfico es un caso emblemático, que ilustra y sintetiza las situaciones anteriormente descritas. De una parte, la inmensa mayoría de mujeres privadas de la libertad por este delito forman parte de los últimos eslabones del tráfico de drogas, y desarrollan principalmente las actividades de mulas o vendedoras al menudeo, más como una forma de subsistencia, para ellas y sus dependientes, que como una opción de ascenso e inclusión social a través de actividades ilícitas. Las historias de vida de muchas mujeres presas por narcotráfico son peculiarmente similares, a pesar de sus evidentes diferencias. Se trata de mujeres que desde jóvenes, incluso niñas, han sufrido el maltrato y la violencia, en buena medida por parte de los hombres (familiares o parejas), quienes han jugado un papel importante en su ingreso a actividades delictivas. Varias de ellas han sido detenidas precisamente por tratar de ingresar drogas a centros de reclusión para que la trafiquen sus parejas o compañeros.

A lo anterior se une el giro punitivo de las últimas décadas frente al tráfico de drogas, el cual ha desempeñado un papel primordial en el vertiginoso aumento de la población carcelaria en diversos países, y particularmente de la población femenina. La respuesta represiva de diversos Estados cae con mayor dureza y de forma selectiva sobre las personas más vulnerables y excluidas. Por esto no es casual que las mujeres que padecen tales condiciones caigan con más frecuencia en el sistema penitenciario y carcelario y lo sufran con mayor rigor. La visión moralista y excluyente que permea la guerra contra las drogas se ensaña con las mujeres y reproduce e intensifica los estereotipos de una criminología positivista y androcéntrica, así como del derecho penal, sobre las mujeres, al verlas como doblemente desviadas: delincuentes y mujeres que se alejan de su rol social y cultural, por lo que merecen un mayor reproche y control. Son malas mujeres, doblemente perversas y merecedoras de castigo. Castigo que se extiende a sus seres cercanos, particularmente a sus hijos, 
muchos de ellos menores de edad y dependienReferencias tes de ellas, pues no existe una figura paterna que se haga cargo, al menos mientras sus madres están en prisión.

Aunque esta visión corre el riesgo de caer justamente en las carencias que acertadamente critica el feminismo, como la maternalización de la mujeres y su construcción, por fuera de un contexto social, como seres frágiles y dependientes, tal riesgo debe eludirse a través de una descripción densa de las mujeres recluidas, que como cualquier otra mujer pueden tener problemas o incluso falta de compromiso en sus roles de madres. Pero aun tomada esta precaución, es innegable que el rol de madres protectoras que una sociedad patriarcal asigna a las mujeres constituye una carga social y cultural que incrementa sus padecimientos en prisión y afecta negativamente la vida de sus hijos.

Por todas las anteriores razones, es imperativo continuar con la senda marcada principalmente por académicas y mujeres activistas en América Latina y otras partes del mundo, así como abrir nuevos caminos con el fin de estudiar y visibilizar, con una perspectiva de género, la experiencia de las mujeres en prisión. Entendida esta como parte de una experiencia social más amplia que se sigue caracterizando por la discriminación y control de las mujeres a partir de construcciones y justificaciones desde una perspectiva excluyente y masculinizada.

1. Almeda, E. (2005). Women's imprisonment in Spain. Punishment and Society, 7(2), 183-199.

2. Antony, C. (2000). Las mujeres confinadas: estudio criminológico sobre el rol genérico en la ejecución y la pena en Chile y América Latina. Santiago de Chile: Editorial Jurídica de Chile.

3. Antony, C. (2006). Estudio sobre violencia de género: las mujeres trasgresoras. Panamá: Instituto de la Mujer de la Universidad de Panamá.

4. Antony, C. (2007). Mujeres invisibles: las cárceles femeninas en América Latina. Nueva Sociedad (208), 73-85.

5. Ariza, L. e Iturralde, M. (2012). En contra de los pobres: justicia penal y prisiones en América Latina. El caso colombiano. En R. Gargarella (Edit.), El castigo penal en sociedades desiguales. Buenos Aires: Miño y Dávila.

6. Bevestrello, Y. y Cortés, P. (1997). Mujeres en conflicto con el sistema penal: estudio descriptivo en relación a la familia y vida intramuro de la población femenina adulta interna en establecimientos penitenciarios. Santiago de Chile: Servicio Nacional de la Mujer/Ministerio de Justicia, División de Defensa Social/Gendarmería de Chile, unicrim.

7. Britton, D. (2000). Feminism in Criminology: Engendering the Outlaw. Annals of the Ame- 
rican Academy of Political and Social Science, 571, 57-76.

8. Carlen, P., \& Worrall, A. (2004). Analysing Women's Imprisonment. Cullompton: Willan Publishing.

9. Caro, B. (1991). Delincuencia femenina en Colombia: IFT-209. Bogotá: Instituto ser de Investigación.

10. Centro de Estudios Legales y Sociales [CELS], Ministerio Público de la Defensa, Procuración Penitenciaria de la Nación y Siglo XXI Editores (Comp.). (2011). Mujeres en prisión. Los alcances del castigo. Buenos Aires: Siglo Veintiuno Editores.

11. Defensoría del Pueblo-Defensoría Delegada para la Política Criminal y Penitenciaria. (2004). Los derechos humanos de la mujer privada de la libertad en Colombia. Obtenido de defensoria: http://www.defensoria.org. co/pdf/informes/informe_111.pdf

12. Hernández, J. (1947). La mujer delincuente en Colombia. Bogotá: Editorial Centro-Instituto Gráfico.

13. Instituto Nacional Penitenciario y Carcelario [INPEC]. (2013). Estadísticas penitenciarias y carcelarias. Obtenido de : http:// www.inpec.gov.co/portal/page/portal/Inpec/SeccionInpeccomoinstitucion/Consolidado_estadistico

14. Jimeno, M. (2004). Crimen pasional: contribución a una antropología de las emo- ciones. Bogotá: Universidad Nacional de Colombia.

15. Lagarde, M. (1993). Los cautiverios de las mujeres: madresposas, monjas, putas, presas y locas. México, D. F.: Universidad Nacional Autónoma de México.

16. Lima, M. (1991). Criminalidad femenina. Teorías y reacción social. México: Porrúa.

17. Marchiori, H. (1999). Criminología: introducción. Córdoba: Marcos Lerner Editora Córdoba.

18. Norza-Céspedes, E.; González-Rojas, A.; Moscoso-Rojas, M. y González-Ramírez, J. (2012). Descripción de la criminalidad femenina en Colombia: factores de riesgo y motivación criminal. Revista Criminalidad 54(1), 339-357.

19. Observatorio de Convivencia y Seguridad Ciudadana. (2007). Rompiendo el silencio. Mujer víctima y victimaria. Bogotá: Secretaría Distrital de Gobierno.

20. Procuraduría Delegada en lo Preventivo para Derechos Humanos y Asuntos Étnicos, Grupo de Asuntos Penitenciarios y Carcelarios. (2006). Mujeres y prisión en Colombia: análisis desde una perspectiva de derechos humanos y género. Bogotá: Autor.

21. Ramírez, R. y Observatorio de Convivencia y Seguridad Ciudadana. (2007). Rompiendo 
el silencio. Mujer víctima y victimaria. Bogotá: Secretaría Distrital de Gobierno.

22. Ramos, P. (2004). Diagnóstico de la situación de las mujeres encarceladas en CoIombia. Obtenido de Centro de Estudios de Justicia de las Américas: http://www. cejamericas.org/index.php/component/ search/?searchword=patricia\%20ramos\&s earchphrase $=$ all\&ltemid $=301$

23. Rodríguez, M. (2004). Mujer y cárcel en América Latina. Obtenido de Centro de Estudios de Justicia de las Américas: http:// www.cejamericas.org/index.php/component/search/?searchword=mujer $\% 20$ y\%20carcel\&ordering=newest\&searchphra se $=$ all\&limit $=20$

24. Smart, C. (1990). Feminist approaches to Criminology or Post modern woman meets atavistic man. In L. Gelsthorpe \& A. Morris (Edits.), Feminist Perspectives in Criminology. Buckingham: Open University Press.
25.Smart, C. (1995). Law, Crime and Sexuality. Essays on Feminism. London: Sage.

26.Smart, C. (1977). Criminological Theory: Its Ideology and Implications concerning Women. The British Journal of Sociology, 28(1), 89-100.

27. Smart, C. (1979). The New Female Criminal: Reality or Myth? British Journal of Criminology, 19(1), 50-59.

28. Uprimny, R. y Guzmán, D. (2010). Políticas de drogas y situación carcelaria en Colombia. En Sistemas sobrecargados. Leyes de drogas y cárceles en América Latina. Recuperado de: http://www.dejusticia.org/files/ r2_actividades_recursos/fi_name_recurso.192.pdf

29. Vizcaíno, M. (2010). Mujeres en la criminalidad: más preguntas que respuestas. Revista Criminalidad, 52(1), 309-330. 